\title{
Why engineering is vital to achieve the UN sustainable development goals post-Covid
}

\author{
Priti Parikh of University College London and Petter Matthews of Engineers Against Poverty say \\ civil engineers will be in even more demand to deliver the United Nations' sustainable \\ development goals in a post-Covid-19 world.
}

Infrastructure has a vital role to play in achievement of the UN's 17 sustainable development goals (SDGs) and 167 targets (EAP, 2020). For example, there are synergies between energy systems and $85 \%$ of the targets (Nerini, et al, 2018), and between sanitation and $77 \%$ of the targets (Parikh et al, 2020).

The Covid-19 pandemic has resulted in a significant loss of human lives and livelihoods worldwide. In reallocating national resources to protect lives and reduce the health and economic impacts of the pandemic, there is an opportunity to continue efforts towards addressing the SDGs through targeted investment in infrastructure (Hansford, 2020).

In low-income countries, nearly one billion people live in slums characterised by high densities, poor environmental conditions and lack of access to basic services. The high densities mean social distancing is simply not feasible (Corburn, 2020). Residents also have to queue at communal water points and poorly maintained public toilets, thereby increasing the risk of further transmission of Covid-19 (Parikh et al, 2020). Limited access to electricity also reduces the effectiveness of public health campaigns that rely on social media.

\section{Crucial role for civil engineers}

The pandemic highlights the urgent need for investment in infrastructure in low-income countries. This is where engineers can play a crucial role in developing high quality, nature-sensitive, low-cost and contextually appropriate solutions.

Examples include networked water and sanitation services, redesign of access routes, flood mitigation measures, solid waste management and access to electricity and communications services. Integration of those services will improve the ability of cities to respond to future pandemics and reduce potential transmission pathways to infectious diseases in local populations.

Consideration must be given to the particular challenges of low-income countries, which often include poor governance and weak institutions. These challenges are exacerbated during the immediate response to crises, when the usual procedures aimed at safeguarding public procurement are relaxed to enable rapid response.

\section{A new generation needed}

Increasing the volume of investment in infrastructure while simultaneously improving governance will require a new generation of civil engineers who are able to use mixed methods, uphold high standards of integrity, work directly with stakeholders and explore innovative frugal design solutions in low-income countries.

The new generation must include graduates of universities based in low-income countries, but this will require investment to build the capacity of academic staff, improve curricula and strengthen links between industry and academia (Matthews et al, 2012 \& Royal Academy of Engineering).

There is also an opportunity to learn the lessons and apply some of the same innovative procedures and design processes developed in low-income countries to high and middle-income countries to support recovery from Covid-19 on a larger platform. By working closely with the civil engineering sector and leveraging the wide-ranging benefits of targeted actions for infrastructure, all nations will be in a stronger position to address the SDGs. 


\section{References}

Corburn, J., Vlahov, D., Mberu, B., Riley, L., Caiaffa, W.T., Rashid, S.F., Ko, A., Patel, S., Jukur, S., Martínez-Herrera, E. and Jayasinghe, S., 2020. Slum health: arresting Covid-19 and improving well-being in urban informal settlements. Journal of Urban Health, pp.110.https://doi.org/10.1007/s11524-020-00438-6

Engineers Against Poverty (EAP) 2000, http://engineersagainstpoverty.org/2020/04/06/six-keychallenges-of-covid-19/, Accessed May 19, 2020

Hansford, 2020. Covid-19 makes delivering on the UN Sustainable Development Goals ever more vital. Accessed from https://www.ice.org.uk/news-and-insight/the-civil-engineer/may2020/covid-19-complicates-delivery-of-unsdgs?_ccCt=GCVh rbAlUZViEW8RwsmlTaKRBXar4UpUI6LIz QK5kP5LroTRIf35BLdDPXGoSX

Matthews, P. et al 2012, Engineers for Africa, Royal Academy of Engineering, London. Available at https://www.raeng.org.uk/publications/reports/engineers-for-africa

Nerini, F.F., Tomei, J., To, L.S., Bisaga, I., Parikh, P., Black, M., Borrion, A., Spataru, C., Broto, V.C., Anandarajah, G. and Milligan, B., 2018. Mapping synergies and trade-offs between energy and the Sustainable Development Goals. Nature Energy, 3(1), pp.10-15.

Parikh, P. Diep, L. Gupte, J and Lakhanpaul, M. nd. Covid-19 Challenges and WASH in Informal Settlements: Taking Action Through the Sustainable Development Goals, Submitted to Cities Journal, 2020

Parikh, Priti, Diep, Loan, Hofmann, Pascale, Tomei, Julia, Campos, Luiza C., Teh, Tse-Hui, Mulugetta, Yacob, Milligan, Ben and Lakhanpaul, Monica, n.d. Mapping Synergies and Trade-Offs between Sanitation and the Sustainable Development Goals (3/9/2020). Available at SSRN: https://ssrn.com/abstract=3552872

Royal Academy of Engineering, Higher Education Partnerships in sub-Saharan Africa, Accessed on 26 May 2020, https://www.raeng.org.uk/global/sustainable-development/africa-grants/highereducation-partnership-sub-saharan-africa

For further information please contact Priti Parikh Tel: +44 (0) 2076792000 Email: priti.parikh@ucl.ac.uk Web: https://www.ucl.ac.uk/civil-environmental-geomaticengineering/research/groups-centres-and-sections/engineering-international-developmentcentre, twitter @pritiparikh73, @EfidUcl

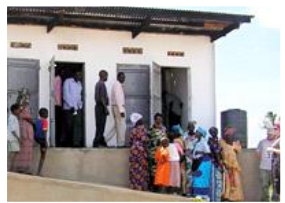

[parikh] Social distancing at communal toilet facilities is not feasible, meaning much greater investment in infrastructure is needed to limit the impact of future pandemics 